\title{
Spontaneous Discharge Rhythms and Social Signalling in the Weakly Electric Fish Pollimyrus isidori (Cuvier et Valenciennes) (Mormyridae, Teleostei)
}

\author{
Bernd Kramer \\ Fachbereich Biologie, Universitāt Konstanz, Postfach 7733, \\ D-7750 Konstanz, Federal Republic of Germany
}

Received December 19, 1977

Summary. The electric organ discharge (EOD) signalling of isolated and of socially interacting Pollimyrus isidori was analyzed.

1. EOD interval histograms of resting animals showed wide ranges with three modes of 12 to $15 \mathrm{~ms}$, of around $92 \mathrm{~ms}$, and of 220 to $230 \mathrm{~ms}$ (Fig. $4 \mathrm{a}$ ). In number and/or position of modes, the $P$. isidori histograms were clearly different from those shown by four other mormyrid species: Gnathonemus petersii, Mormyrus rume, Brienomyrus niger, Brienomyrus brachyistius.

2. The EOD interval histograms of swimming P. isidori (Fig. 4a) displayed only one mode of around $50 \mathrm{~ms}$ and closely resembled the EOD activity exhibited by $G$. petersii, $B$. niger, and $B$. brachyistius.

3. During overt attack (Figs. 4b, 6, 7a), P. isidori displayed high discharge rates as do $G$. petersii, $B$. niger, and $M$. rume. The EOD time patterns of the displays were clearly distinct from the other species' displays.

4. These data suggest the possibility that mormyrids might recognize conspecifics from their resting- or attack-associated EOD time patterns, not, however, by monitoring EOD swimming activity. During this behavior, species identification would seem possible only by the analysis of spectral cues from the properties of the individual EOD pulses (cf. Fig. 3). Compared with the other species mentioned above, the extremely short EOD of $P$. isidori contains much more energy in a high frequency band (peak: $10 \mathrm{kHz}$ with energy beyond $30 \mathrm{kHz}$ ).

5. Different individuals of $P$. isidori displayed either a Preferred Latency Response of approx. 12 to $14 \mathrm{~ms}$ or a response consisting in avoiding a 10 to $20 \mathrm{~ms}$ discharge latency to foreign electrical stimuli (Figs. 8-10). While the avoidance response may be considered a jamming avoidance behaviour, reducing the probability of coincidences with a conspecific's EODs, the Preferred Latency Response in $P$. isidori would have the opposite effect and 'jam' a conspecific's signals when the latter displays high discharge rates occurring during attack behaviour. Whether these alternative types of latency behaviour are sex, age, or rank correlated remains to be investigated. 


\section{Introduction}

The purpose of the present paper is to extend our knowledge of the electric discharge time patterns of mormyrid fish and their significance for signalling and communication. EODs as social signals have been investigated so far only in three species of mormyrids: Gnathonemus petersii, Mormyrus rume, and Brienomyrus niger (Moller, 1970; Moller and Bauer, 1973; Bauer, 1972, 1974; Bauer and Kramer, 1973, 1974; Kramer, 1974, 1976a, b, c; Kramer and Bauer, 1976; Bell et al., 1974; Russell et al., 1974). In Marcusenius cyprinoides the presence or absence of electric signals was shown to influence schooling behaviour and group cohesion (Moller, 1976).

The problem as to whether species identification and communication in mormyrids is performed by means of properly tuned electroreceptors acting as filters detecting spectral cues of their own and conspecific EODs (Scheich et al., 1973; Hopkins, 1976; Bastian, 1976 b) or whether the biologically relevant information is contained in the highly variable EOD time patterns has hardly been dealt with. Much more information on possible special adaptations and differential strategies concerning electric signalling and separation of signals in a noisy environment is needed for understanding the etho-ecology and the evolution of the behaviour of this group of fish.

\section{Material and Methods}

The fish were maintained in $300 \mathrm{l}$-aquaria (one for each species) which were supplied with plants and many porous pot hiding places. Water conditions of the experimental and the home tanks were: $26 \pm 0.2^{\circ} \mathrm{C}$; electrical resistivity: 2.5 to $2.9 \mathrm{k} \Omega \cdot \mathrm{cm}$ (conductivity: 4.0 to $3.45 \mu \mathrm{S} / \mathrm{cm}$ ); total hardness: $0.8 \mathrm{mg} \mathrm{CaO}$ plus $\mathrm{CaSO}_{4} / \mathrm{l}(0.5 \mathrm{mg} \mathrm{CaO} / 1)$; $\mathrm{pH}$ was 8.2 . The water was power filtered by synthetic fibre and peat. The fish were maintained on a $12 \mathrm{~h} / 12 \mathrm{~h}$ light-dark cycle (light from $7 \mathrm{~h}$ to $19 \mathrm{~h}$ ). The animals were fed daily with Chironomus larvae or Tubifex worms.

Six Pollimyrus isidori of unknown sex (standard length $7.1-8.5 \mathrm{~cm}$, weighing $6.0-8.7 \mathrm{~g}$ ), identified according to Taverne (1971) were used in the experiments. One of the individuals which was found to be electrically silent-although in apparently excellent condition otherwise-was used to elicit attacks when put into the tanks with the experimental animals for five minutes. A parallel series of attack experiments were performed with a heterospecific mormyrid (Brienomyrus brachyistius (Gill), Taverne, 1971). Head-to-tail peak-to-peak voltages, measured in water as given above, ranged from $80 \mathrm{mV}$ to $150 \mathrm{mV}$ in $P$. isidori and from 330 to $570 \mathrm{mV}$ in B. brachyistius. EODs were tape-recorded by two small silver ball electrodes placed at the small sides of the experimental tanks $(0.5 \times 0.3 \times 0.3 \mathrm{~m} ; 45 \mathrm{l})$, together with a voice record of the behaviour. The pulse trains were analyzed on a Nicolet 1074 signal averaging system. The data stored in this device were output on BCD paper tapes which were read and the data transferred to magnetic tape files in the computer centre of the University of Konstanz. The data were further analyzed by programs written in Fortran IV for interspike interval analysis (Kramer 1974, 1976 c).

It was not possible to separate electronically the pulses of pairs of freely interacting $P$. isidori and $B$. brachyistius. Therefore, inter-discharge intervals of such records were measured on oscilloscope films by hand (cf. Kramer, 1976c).

Stimulation experiments were carried out by using a dipole model which approximately simulated the electric field of a conspecific. The model consisted of small silver ball electrodes mounted on a transparent plastic rod and had no physical resemblance to a fish. The model was placed at $5 \mathrm{~cm}$ distance and parallel to the unrestricted fish which was hiding in a porous pot. The model was separated from the stimulus generator by a transformer. The fish was stimulated with 
slightly 'rounded' rectangular, monopolar $0.2 \mathrm{~ms}$ pulses of an amplitude equal to the peak-to-peak amplitude of the fish. Since the fish was unrestricted, it could assume both a head-negative and a head-positive position relative to the model.

Experiments and recordings were done during the day between $1000 \mathrm{~h}$ and $1600 \mathrm{~h}$.

\section{Results}

\section{Analysis of EOD Waveforms}

Figure 1 shows anaesthetized individuals of $P$. isidori and B. brachyistius, and Figure 2 the waveforms of their respective EODs. The discharge of $P$. isidori is characterized by a rapid head-negative main phase which was preceded and followed by slower head-positive potentials of considerably lower amplitude. The duration of the main phase of approx. $50 \mu$ s (positive peak to positive peak) was extremely short. The total duration of the pulse was approx. $250 \mu \mathrm{s}$.

The rather complex EOD of B.brachyistius consists of two main phases, preceded and followed by slower head-negative and head-positive potentials of low amplitude. The very long prepotential (approx. $300 \mu \mathrm{s}$ ) apparently consists of two components. The total duration of the discharge was approx. $1.5 \mathrm{~ms}$.

Linear amplitude spectra ${ }^{1}$ of both discharges are given in Figure 3 . The spectrum of the $P$. isidori discharge exhibited a single peak at around $10 \mathrm{kHz}$ with energy beyond $30 \mathrm{kHz}$. The spectrum of the $B$. brachyistius discharge

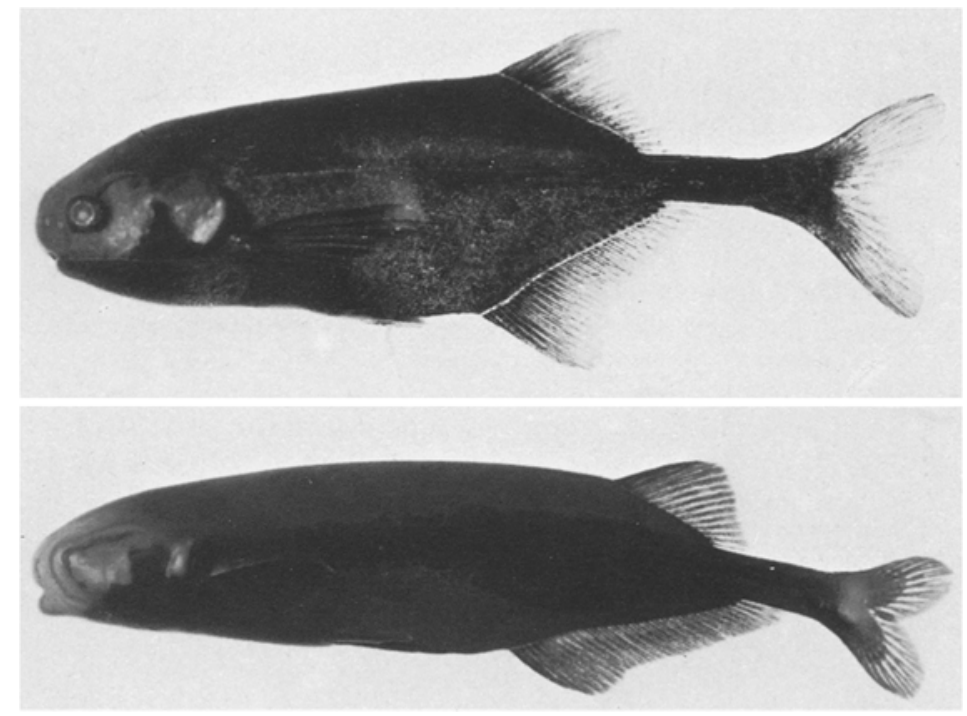

Flg. 1. Pollimyrus isidori (above; $8 \mathrm{~cm}$ ) and Brienomyrus brachyistius (below; $10 \mathrm{~cm}$ )

\footnotetext{
1 Fast Fourier Transformation routine according to G.D. Bengley, executed on the HP 21 MX computer in the laboratory of Prof. Scheich, TH Darmstadt (resolution: $48 \mathrm{~Hz}$, sampling rate: $100 \mathrm{kHz}$ ). The EODs had previously been stored on a Kyberna 601 instrumentation tape recorder at $76 \mathrm{~cm} / \mathrm{s}$ (frequency response $\pm 3 \mathrm{~dB}$ from 0.15 to $150 \mathrm{kHz}$ ). For $\mathrm{A} / \mathrm{D}$ conversion the tape was edited at $19 \mathrm{~cm} / \mathrm{s}$. I thank Dr. Camargo and Prof. Scheich for their generous support
} 


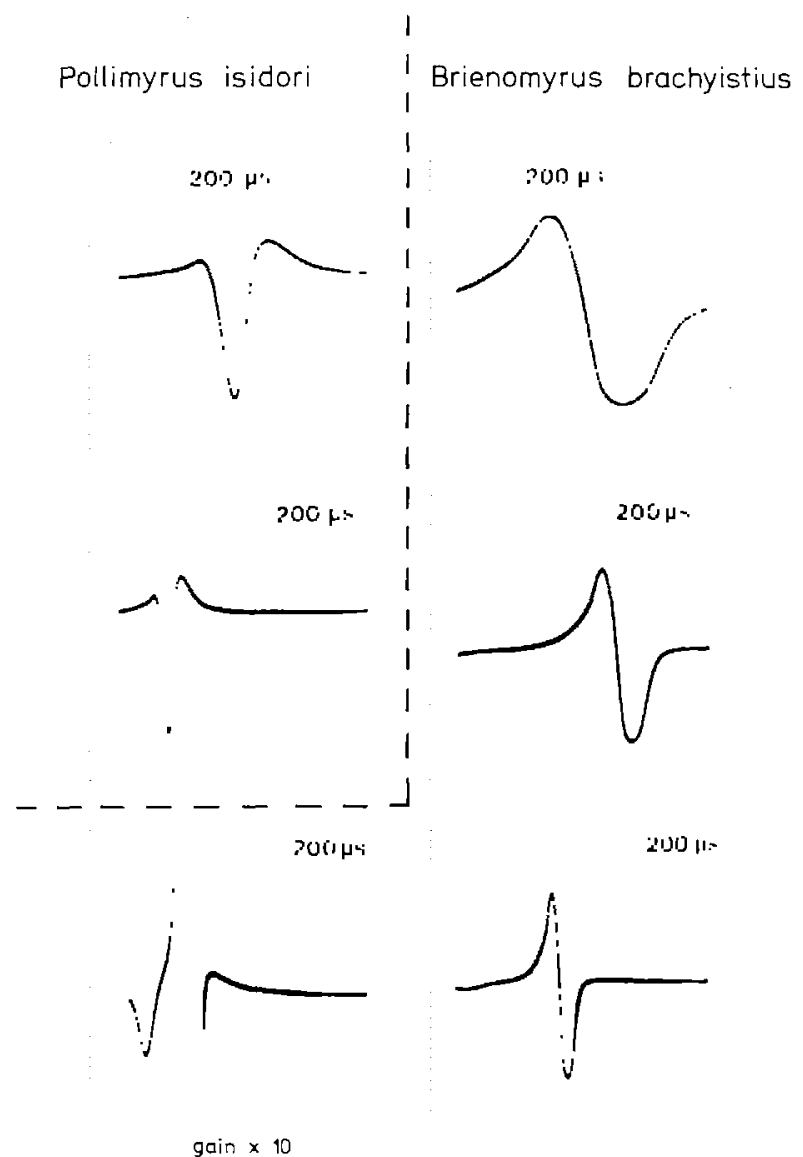

Fig. 2. Waveforms of the electric organ discharges of one individual of $P$. isidori and of one individual of $B$. brachyistius at variable sweep speeds. The waveforms of the EODs of another four $P$. isidori and of another ten $B$. brachyistius looked exactly like those shown here. Lower left figure: high gain to show low-amplitude pre- and after-potential of $B$. brachyistius discharge. Rapid potential change between the peaks not recorded on the oscilloscope (Tektronix 7000 series) storage screen. Stainless steel electrodes, head-positivity up

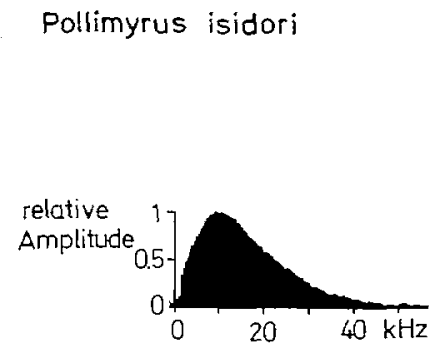

Brienomyrus brochyistius

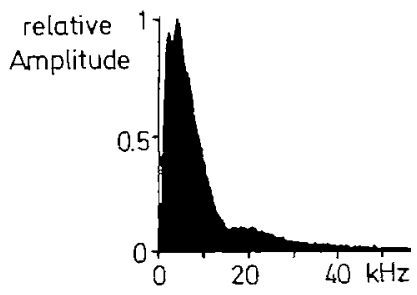

Fig. 3. Linear amplitude spectra of the EODs of $P$. isidori and B. brachyistius 


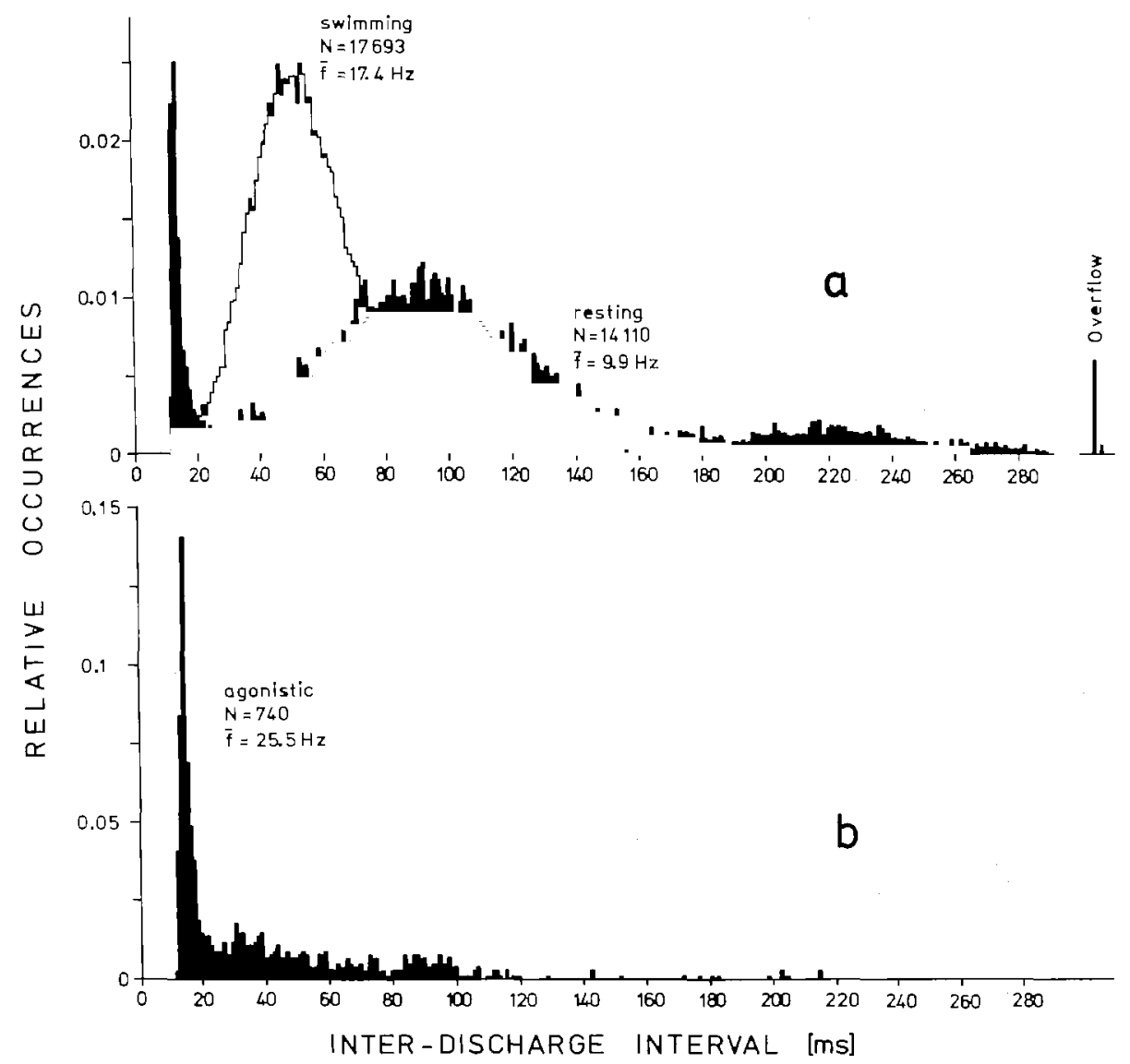

Fig. 4 a and b. Inter-discharge interval histograms of $P$. isidori. a black histogram: activity exhibited by an isolated individual resting immobile (except gill movements) between plants; white histogram: isolated, continuously swimming individual. b histogram exhibited by an individual attacking a conspecific. Ordinate: relative occurrences of EODs per $1 \mathrm{~ms}$ bin; abscissa: duration of interdischarge intervals in ms. $N$, total number of intervals analyzed; $\bar{f}$ mean EOD repetition rate $(\mathrm{Hz})$. Note the close matching of the high discharge rate mode of the resting histogram with the single mode of the agonistic histogram

displayed three peaks at $2.1,4.4$, and around $20 \mathrm{kHz}$, with almost no energy beyond $30 \mathrm{kHz}$. In the $P$. isidori spectrum little energy was found below $1.5 \mathrm{kHz}$ which is in contrast to the $B$. brachyistius spectrum.

\section{Interval Distributions}

Resting, isolated individuals of $P$. isidor $i$ which lay between plants on the bottom of their tanks, and which were immobile except for gill movements displayed inter-pulse interval histograms with three modes (an example is given in Fig. 4 a, black histogram). Consequently, there were three preferred discharge rates. Inter- 


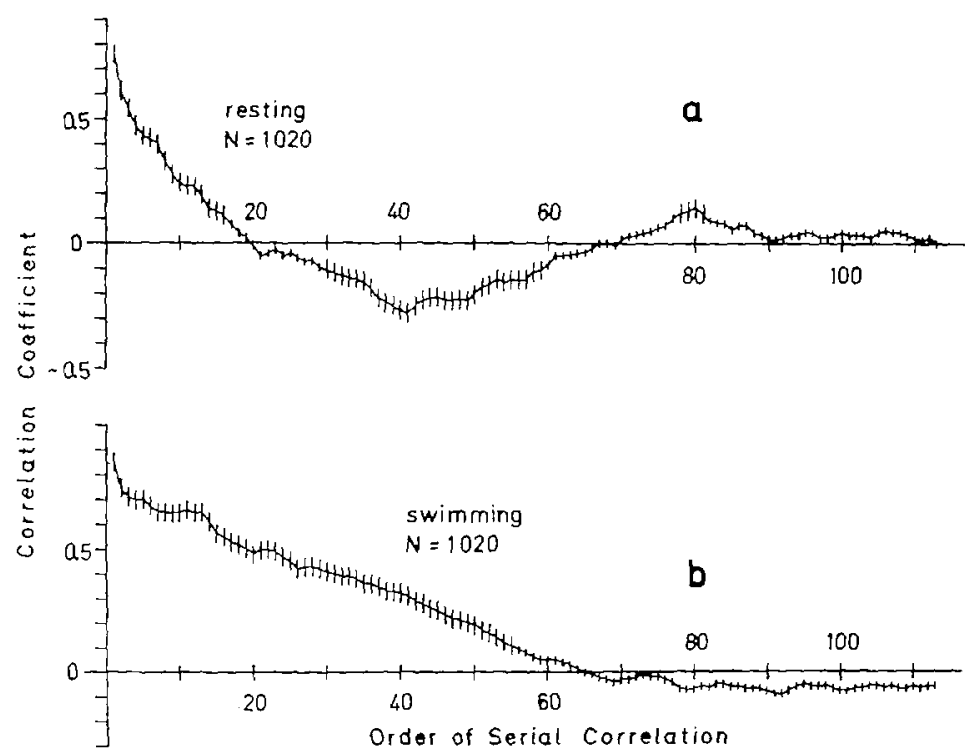

Fig. 5 a and b. Serial correlograms of interpulse interval sequences of $P$. isidori emitted during resting and swimming $\mathbf{b}$. Large vertical bars: correlation coefficients significant at a confidence level of $P<0.001$ as tested by the non-parametric Wald-Wolfowitz test (cf. Kramer, 1974)

vals of the mode of highest rate were of around $12-15 \mathrm{~ms}$, the intervals of the medium rate mode of approx. $92 \mathrm{~ms}$, and the intervals of the low rate mode of 220-230 ms. Especially the last mode varied between individuals, and intervals tended to become shorter when the animals did not stay completely quiet. The mean discharge rate was near $10 \mathrm{~Hz}$.

The histograms of swimming animals displayed only one mode around $50 \mathrm{~ms}$ (Fig. 4a, white histogram). The mean discharge rate was approx. $17 \mathrm{~Hz}$.

When attacking a conspecific (Fig. $4 \mathrm{~b}$; in this case the attacked conspecific was the electrically silent one), there was also only one mode in the interval histogram. However, this mode $(14.5 \mathrm{~ms})$ was virtually identical with the high discharge rate mode of the resting activity histogram. The mean discharge rate was around $25 \mathrm{~Hz}$. Thus in total there were four modes, one of which (50 ms) was only shown by isolated, swimming animals. The high discharge rate was shown during absolute immobility (except gill movements) as well as during vigorous swimming activity in agonistic behaviour.

\section{Sequential Order of Intervals}

The sequential order in which intervals of different length occur is shown in Figure 5. Resting P. isidori (Fig. 5a) displayed runs of approx. 16-21 intervals which tended to be similar in length. The correlogram started with rather high values $(>0.7)$ which means that adjacent intervals were kept close in size. With an increasing number of intervals separating two intervals, the correlation 


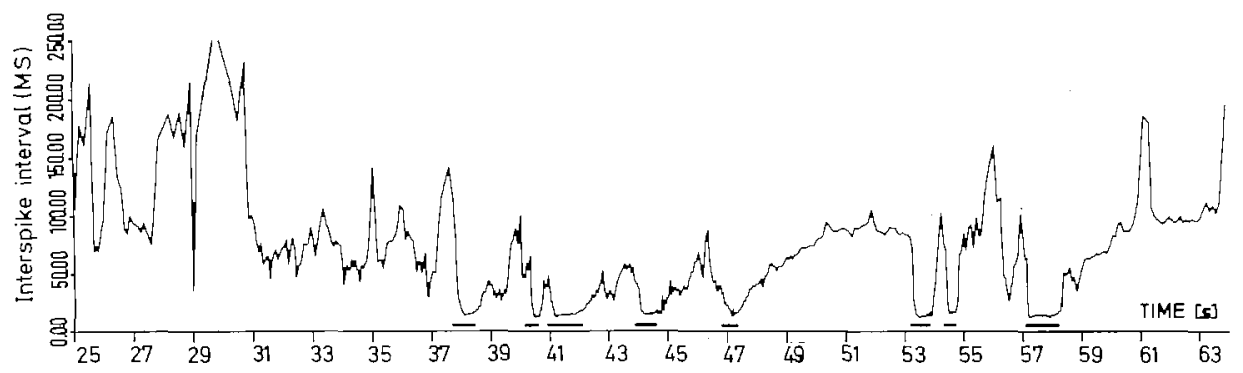

Fig. 6. Sequential representation of a $P$. isidori's discharge activity during agonistic behaviour, directed at an electrically silent conspecific. The abscissa of each point is the time of occurrence (in s) of each discharge, and the ordinate is the interval (in $\mathrm{ms}$ ) from the previous discharge. High discharge rate bursts accompanying overt attack directed at the silent conspecific are underlined by horizontal bars

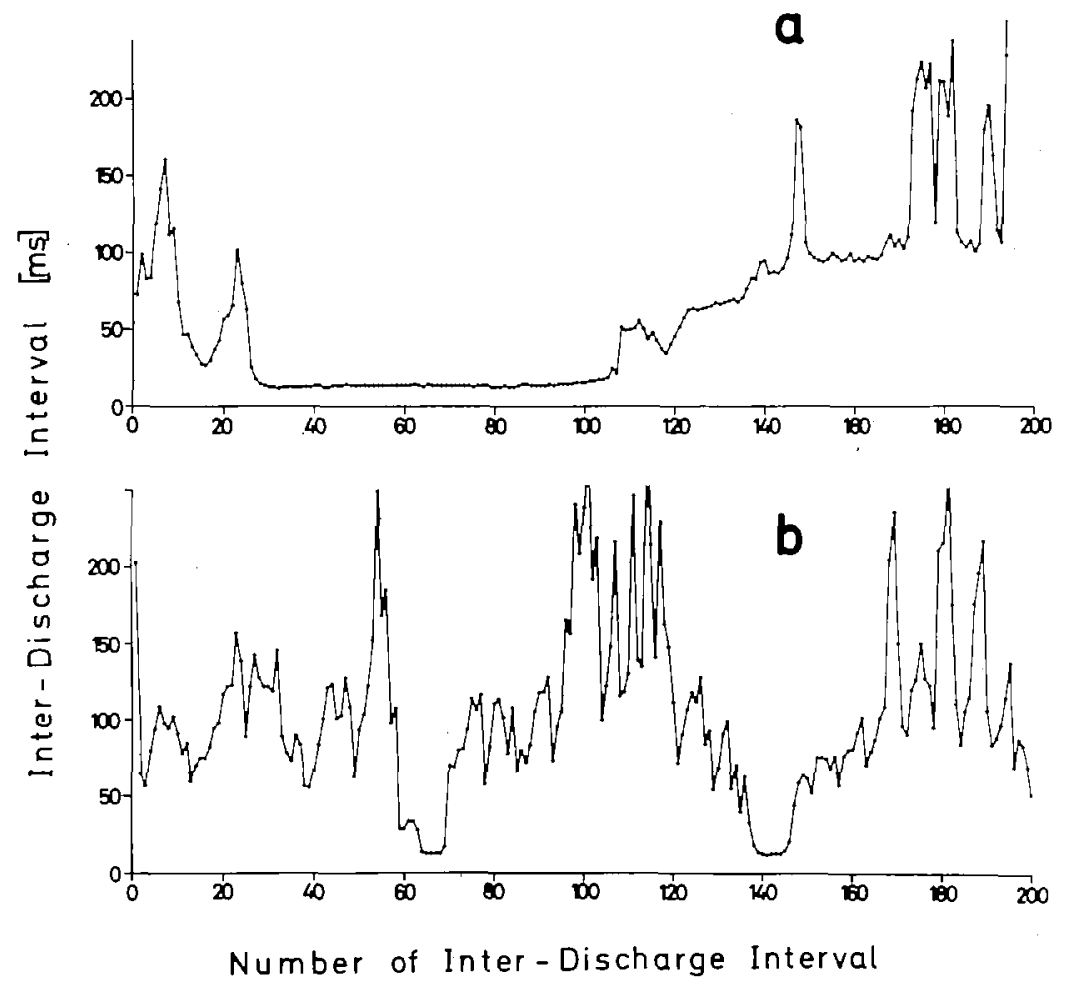

Fig. 7. a Sequential representation of an individual high discharge rate emitted by $P$. isidori during overt attack directed at a conspecific. Each point is one interval, plotted sequentially on the abscissa: The ordinate is the length of each interval. b shows the discharge activity of $P$. isidori during rest. Note that 'bursts' emitted during rest are much shorter than the attack-associated ones. The durations of the sequences shown are $11.24 \mathrm{~s}$ (a) and $20.87 \mathrm{~s}$ (b) 


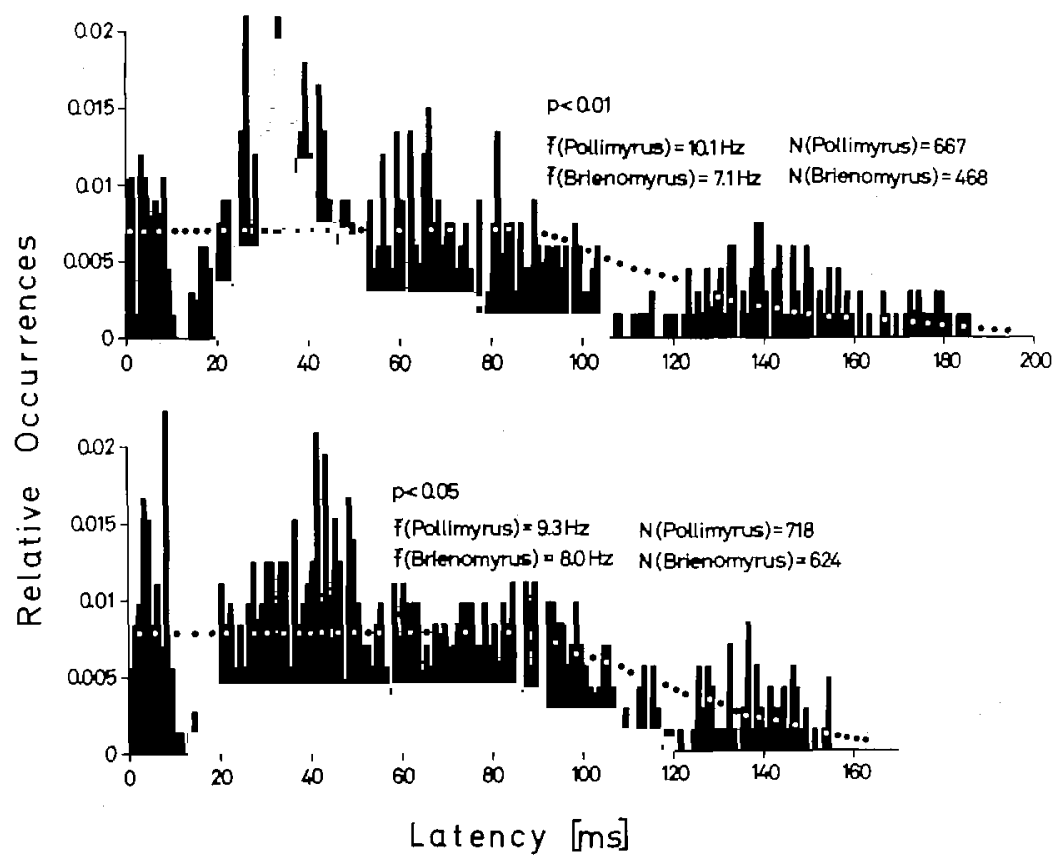

Fig. 8. Histograms of the latencies of $P$. isidori pulses to $B$. brachyistius pulses (two different individuals of $B$. brachyistius). The fish were close to each other, no overt attacks were observed. $N$, total number of pulses. $\bar{f}$, mean $\mathrm{EOD}$ rates. The distributions obtained were tested for significance of differences as compared to the random distributions (cf. Kramer, 1974), indicated by dots, by a Kolmogorov-Smirnov test. Note the avoidance of EOD latencies of approx. 10 to $20 \mathrm{~ms}$ to the $B$. brachyistius discharges, occurring at time $=0$

coefficients declined rather steadily which means that there were no short-term discharge rate variations superimposed on the main discharge rhythm as, e.g., in G. petersii (Kramer, 1974). After a period of intervals which were not regulated with respect to the first one, there followed another run of intervals (from the 30 th to 40 th until the 59 th to 74 th interval) which were significantly negatively correlated with respect to the first one. There could also be a second run of a few intervals positively correlated with the first one (around the 80 th to 95 th interval). The amplitude of the oscillations was, of course, damped with an increasing number of separating intervals.

The correlograms of EOD activity during swimming were characterized by runs of 16-55 positively correlated intervals which started with high correlation coefficients. The decline to zero was rather steady. In contrast to the resting EOD activity, there were no significantly negatively correlated runs of intervals. Discharge rate regulation of 'distant' runs of intervals was either lacking (correlation coeffioients not significantly different from zero) or there could be one or a few more positively correlated runs of intervals at varying distances from the first one. Together with the steady decline of the significant correlation coefficients this shows that fluctuations around the central discharge rate were due to random jitter. 

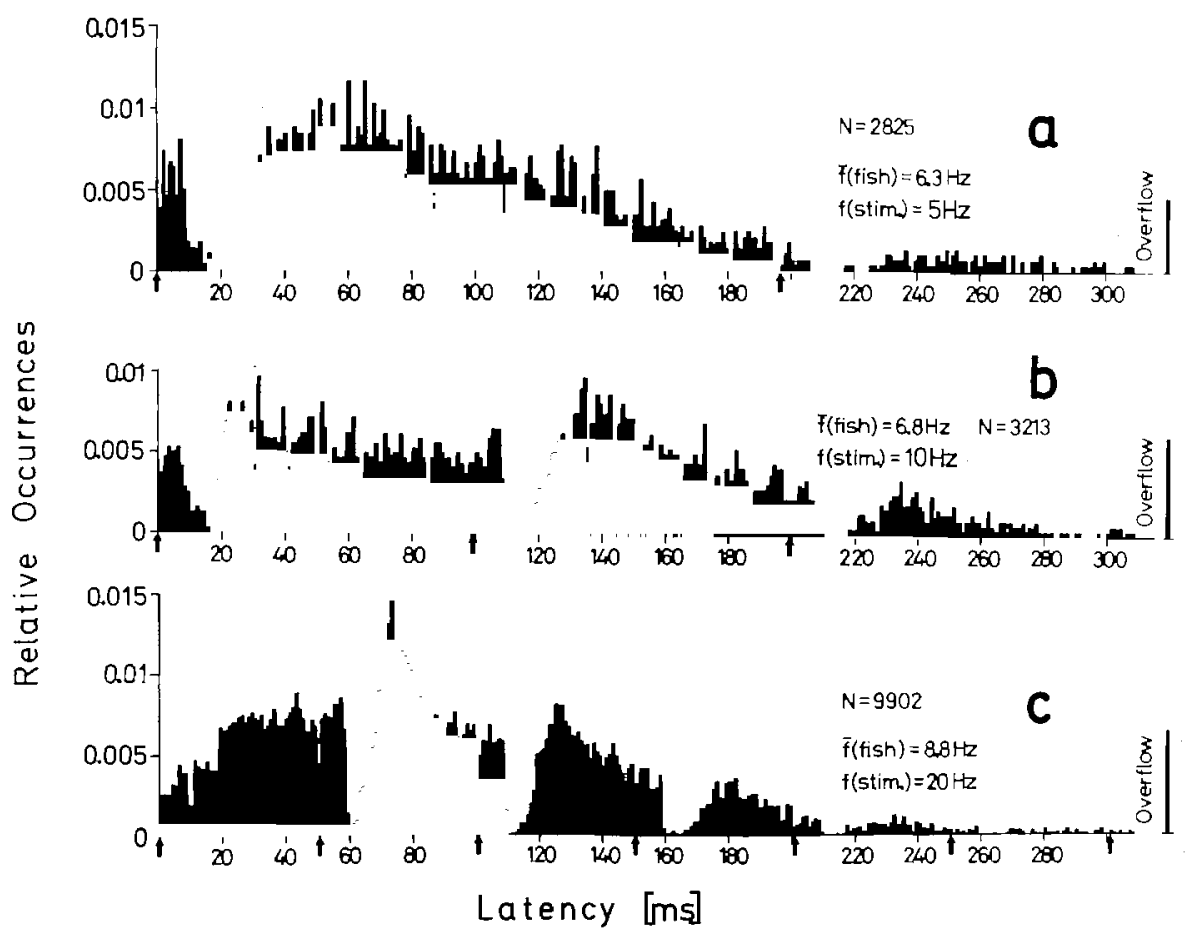

Fig. 9a-c. Histograms of the intervals of $P$. isidori pulses to free-running stimulus pulses of a $5 \mathrm{~Hz}, \mathbf{b} 10 \mathrm{~Hz}$, c $20 \mathrm{~Hz}$ repetition rate. Especially at higher stimulus repetition rate the animal 'skips' one or more stimuli before discharging. Times of occurrence of stimuli as indicated on the abscissa by arrows. Note the avoidance of EOD latencies within the interval of approx. 10 to $20 \mathrm{~ms}$ to the stimulus at all stimulus repetition rates. $N$, number of EODs emitted by $P$. isidori. $f$, $P$. isidori's mean EOD rate during stimulation

\section{Social Signals During Agonistic Behaviour}

During overt attack a conspicuous type of discharge activity was shown which was characterized by a rapid increase of discharge rate (Figs. 6, 7 a) to a high level. The high discharge rate was maintained for periods from one-half to more than one second, or 25 to 84 intervals below $30 \mathrm{~ms}$. Compared with these bursts the bursts shown during resting activity were only short-lived (7 to 10 intervals below $30 \mathrm{~ms}$, compare Fig. $7 \mathrm{~b}$ ). During attacks, discharge rate increase from low rate inter-burst activity occurred within 5-11 intervals to the rather steady high discharge rate. At the end of the bursts the discharge rate decelerated during 3 to 19 intervals to the low rate inter-burst activity. The shortest intervals encountered during individual bursts ranged from 11.6 to $15.3 \mathrm{~ms}$.

\section{EOD Latency Responses}

One out of four $P$. isidori, presented with a heterospecific $B$. brachyistius in their home tanks, responded to the discharge train of the latter by avoiding 


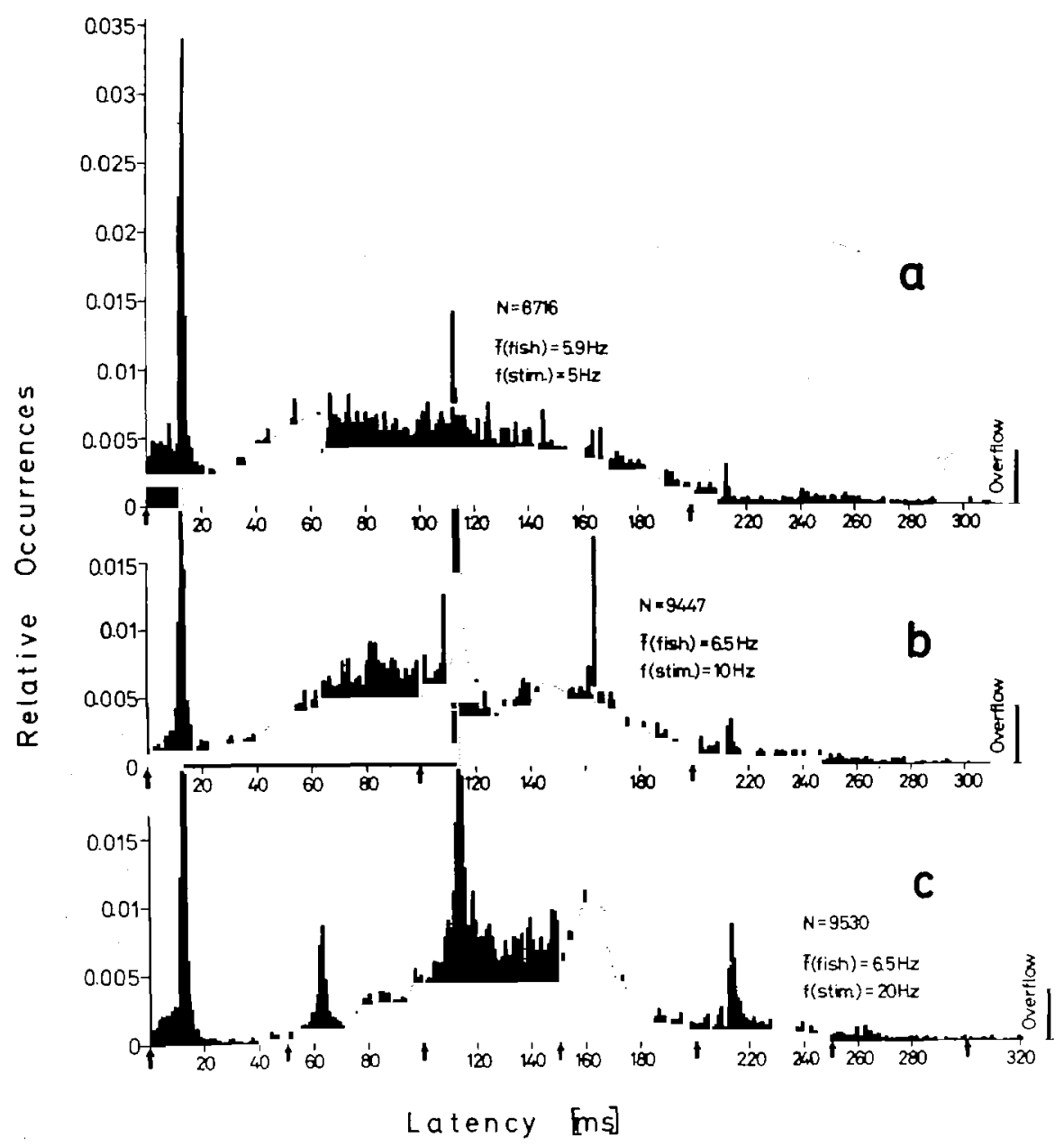

Fig. 10a-c. Histograms of the intervals of $P$. isidori pulses to free-running stimulus pulses of a $5 \mathrm{~Hz}, \mathbf{b} 10 \mathrm{~Hz}, \mathbf{c} 20 \mathrm{~Hz}$ repetition rate. As Figure 9 but in this animal a Preferred Latency Response instead of an avoidance of 10 to $20 \mathrm{~ms}$ latencies was observed

to discharge during a certain time interval (approx. 10-20 ms) to the $B$. brachyistius discharge (Fig. 8). As Russell et al. (1974) pointed out, the threshold of the latency response in $G$. petersii is rather high, so when freely interacting fish are too far apart from each other no latency response, of course, may be expected. For this reason stimulation experiments were carried out using a dipole model placed near the shelter in which the animal was hiding. On stimulation via the dipole model with short pulses at fixed rate two other animals also showed an EOD avoidance response at the same latency (10 to approx. $16 \mathrm{~ms}$; Fig. 9). Under the same conditions, however, two further animals exhibited a latency preference response (12-14 ms; Fig. 10).

By close inspection of the histograms it was found that some of the latency preference responses showed short EOD avoidance periods of approx. one 
ms just ahead of the EOD preference periods, as if he probability of one type of two mutually exclusive responses might increase when the other declines.

\section{Discussion}

The main concern of the present study was to describe the electric signalling of $P$. isidori in comparison with the signalling of other species. This was done with the question in mind whether species recognition and communication would be possible on the basis of species-specific EOD time patterns.

A feature common to all of the few species investigated, present also in $P$. isidori, was the very wide range of intervals displayed during resting (cf. also Bauer, 1974) as compared with the EOD activity which is observed during swimming (Kramer, 1974 and 1976 a, c; Kramer and Bauer, 1976). Characteristic for each species seems to be the number (two or three) and/or position of modes of the time histograms, as well as the discharge rhythms (Bauer, 1974; Kramer, 1974, 1976 c). P. isidori, e.g., displayed conspicuous oscillations in the correlograms (Fig. 5) not found in other species. From these data, it would not seem impossible that the fish might monitor one of these parameters, or, more likely, a combination of them, in order to analyze temporal patterns. This would allow species recognition, or, conversely, broadcasting of the identity of a territory-owner to nearby or approaching fish.

The EOD activity displayed by P. isidori during swimming (Fig. $4 \mathrm{a}$, white histogram, and Fig. 5 b) resembled closely that displayed by G. petersii (Kramer, 1974; Bauer and Kramer, 1976) and B. niger (Kramer, 1976c). As in P. isidori, the histograms of these species (and also of B. brachyistius, unpublished) displayed only one mode around $50 \mathrm{~ms}$. The interval ranges of these distributions were narrow compared to those found in the resting histograms. In the three species, $B$. niger, G. petersii, and $P$. isidori, the mechanisms of successive interval length regulations were simple and virtually identical: correlation coefficients declined steadily as the number of intervals separating two intervals increased. If these species formed schools during migrations e.g., from day-time hiding areas to night-time feeding grounds, as does Marcusenius cyprinoides (Moller, 1976), the different species, locking into a similar discharge rate, might coexist within one heterospecific school and move about together. The EODs would aid in maintaining group cohesion (Moller, 1976).

The exception among these species is Mormyrus rume which discharges at intervals approx. twice the duration of the intervals displayed by the other species during swimming behaviour (around $110 \mathrm{~ms}$, Kramer, 1976a).

The attack-associated EOD burst activity displayed by $P$. isidori (Figs. $4 \mathrm{~b}$, 6,7 a) differed clearly from that displayed by any one of the other species investigated. In contrast to $P$. isidori, B. niger and $M$. rume displayed very short bursts at a maximal EOD rate which was by far lower than in P. isidori (Kramer, 1976 a, c). G. petersii's attack displays exhibited a double pulse (short-long) feature absent in $P$. isidori. In addition, these displays were terminated abruptly by an EOD break (Kramer and Bauer, 1976), not yet found in any other species. The displays exhibited by $M$. rume and $B$. niger also were clearly different 
from each other in maximal discharge rate and in the way the high discharge rate decreased (Kramer, 1976a, c). Although all mormyrid attack-associated EOD displays, as analyzed up to now, essentially consist of a discharge rate increase it may tentatively be concluded that these displays, differing so widely, are species-specific and would allow rapid species identification. In most fish, attack-behaviour plays an important role in courtship; thus an important role of these displays might be a function as a premating isolating mechanism.

Species recognition on the basis of EOD time pattern analysis would thus be possible by monitoring another individual's resting or attack-associated EOD activity, not, however, by monitoring swimming activity (with the exception of $M$. rume). During swimming activity, only spectral analysis of the individual pulses would allow species identification.

$P$. isidori displays one of the shortest electric organ discharges among mormyrids (Fig. 1). As the amplitude spectrum of the pulse shows there is a considerable amount of energy beyond $30 \mathrm{kHz}$ (peak: $10 \mathrm{kHz}$, Fig. 2). For comparison, the amplitude spectrum of the discharge of Gnathonemus petersii shows a peak at $5 \mathrm{kHz}$ and decays to almost zero at $20 \mathrm{kHz}$ (Boudinot, 1972). The $B$. niger EOD exhibits an amplitude maximum at slightly below $5 \mathrm{kHz}$ which decays to almost zero at $15 \mathrm{kHz}$ (Heiligenberg, 1976). Among this small sample of species, $P$. isidori could theoretically filter its species' signals out of a noisy environment by the use of appropriately tuned electroreceptors (Scheich et al., 1973; Hopkins, 1976; Bastian, 1976b). While such a mechanism might also exist for the two species reported upon in this paper (note, e.g., the large difference in the amplitudes of low frequencies in the spectra presented in Fig. 3) it remains doubtful whether the quality of the analyzing sensory systems would allow to discriminate between EODs with more similar power spectra characteristics (c.g. G. petersii and B. niger, see above). In the gymnotid fish Eigenmannia, a time domain analysis of the electric signal relying on temporal patterns has been demonstrated (Scheich, 1977).

At least some mormyrid fishes (best investigated species: G. petersii) may phase-lock their EODs to a stimulus discharge train (Bauer and Kramer, 1974), apparently in an effort to reduce the occurrence of discharge coincidences (Kramer, 1974; Russell et al., 1974) and to protect the power of their electrolocation system (Heiligenberg, 1976, 1977). The latency response to electrical stimuli (either from another mormyrid or from a dipole) was found to differ between individuals in $P$. isidori: two animals exhibited a Preferred Latency Response similar to $G$. petersii (Fig. 10), three others displayed a response which consisted in avoiding a 10 to $20 \mathrm{~ms}$ discharge latency (Figs. 8 and 9). It was not possible to detect any morphological differences between the individuals of both kinds. Furthermore, EOD waveforms looked exactly alike. All of the animals were bought from one tropical fish dealer's in one group and kept together in the same tank before the experiments.

Two types of latency behaviour have also been reported in $B$. niger (Heiligenberg, 1976). In this species, the type of latency response expected depended on the momentary EOD rate of the animal, so that one animal responded by different EOD latency behaviours at different times. In $P$. isidori, however, two subgroups of individuals were found responding differently to foreign stimuli 
independent at least of EOD mean rates. If the animals really belong to the same species (or subspecies), the observation of two subgroups of individuals displaying alternative latency response behaviours might prove to be highly interesting for social communication.

The avoidance of a 10 to $20 \mathrm{~ms}$ discharge latency could, of course, be explained as a jamming avoidance behaviour when considering its implications for the discharge interactions between two resting or attacking conspecific partners (Fig. $4 \mathrm{a}$ and b). By avoiding to discharge at a 10 to $20 \mathrm{~ms}$ interval to the conspecific's last discharge a $P$. isidori would reduce the probability of EOD coincidence with the partner's next discharge. On the contrary, a $P$. isidori displaying the Preferred Latency Response would increase the probability of EOD coincidence with the partner's next discharge. This might in turn cause the conspecific partner to avoid the high discharge rate observed mainly during attack. It would be interesting to know whether the display of a certain type of latency response was associated with social rank, age, or sex. This remains to be investigated.

Acknowledgements. I wish to thank Prof. Dr. H, Markl for his critical reading of the manuscript.

\section{References}

Bastian, J.: Frequency response characteristics of electroreceptors in weakly electric fish (Gymnotoidei) with a pulse discharge. J. comp. Physiol. 112, 165-180 (1976 b)

Bauer, R.: High electrical discharge frequency during aggressive behaviour in a mormyrid fish, Gnathonemus petersii. Experientia 28, 669 (1972)

Bauer, R.: Electric organ discharge activity of resting and stimulated Gnathonemus petersii (Mormyridae). Behaviour 50, 306-323 (1974)

Bauer, R., Kramer, B.: Relations entre le comportement agressif du Mormyridé Gnathonemus petersii et sa décharge électrique. J. Physiol. (Paris) 67, 240-241 A (1973)

Bauer, R., Kramer, B.: Agonistic behaviour in mormyrid fish: latency-relationship between the electric discharges of Gnathonemus petersii and Mormyrus rume. Experientia 30, 51-52 (1974)

Bell, C.C., Myers, J.P., Russell, C.J.: Electric organ discharge patterns during dominance related behavioural displays in Gnathonemus petersii (Mornyridae). J. comp. Physiol, 92, 201-228 (1974)

Boudinot, M.: Contribution à l'étude des caractéristiques électriques de l'organe effecteur de Gnathonemus petersii. Mémoire présenté au conservatoire national des Arts et Métiers pour obtenir le diplôme d'ingénieur C.N.A.M., Paris (1972)

Heiligenberg, W.: Electrolocation and jamming avoidance in the mormyrid fish Brienomyrus. J. comp. Physiol. 109, 357-372 (1976)

Heiligenberg, W.: Principles of electrolocation and jamming avoidance in electric fish. A neuroethological approach. In: Studies of brain function. Braitenberg, V., Barlow, H.B., Florey, E., Grüsser, O.-J., van der Loos, H., (eds.), Vol. 1. Berlin, Heidelberg, New York: Springer 1977

Hopkins, C.D.: Stimulus filtering and electroreception: tuberous electroreceptors in three species of gymnotid fish. J. comp. Physiol. 111, 171-207 (1976)

Kramer, B.: Electric organ discharge interaction during interspecific agonistic behaviour in freely swimming mormyrid fish. A method to evaluate two (or more) simultaneous time series of events with a digital analyser. J. comp. Physiol. 93, 203-235 (1974)

Kramer, B. : Electric signalling during aggressive behaviour in Mormyrus rume (Mormyridae, Teleostei). Naturwissenschaften 63, 48 (1976a)

Kramer, B.: Flight-associated discharge pattern in a weakly electric fish, Gnathonemus petersii (Mormyridae, Teleostei). Behaviour 59, 88-95 (1976 b) 
Kramer, B.: The attack frequency of Gnathonemus petersii towards electrically silent (denervated) and intact conspecifics, and towards another mormyrid (Brienomyrus niger). Behav. Ecol. Sociobiol. 1, $425446(1976 \mathrm{c})$

Kramer, B., Bauer, R. : Agonistic behaviour and electric signalling in a mormyrid fish, Gnathonemus petersii. Behav. Ecol. Sociobiol. 1, 45-61 (1976)

Moller, P.: 'Communication' in weakly electric fish, Gnathonemus niger (Mormyridae). I. Variation of electric organ discharge (EOD) frequency elicited by controlled electric stimuli. Anim. Behav. 18, 768-786 (1970)

Moller, P.: Electric signals and schooling behaviour in a weakly electric fish, Marcusenius cyprinoides L. (Mormyriformes). Science 193, 697-699 (1976)

Moller, P., Bauer, R.: 'Communication' in weakly electric fish, Gnathonemus petersii (Mormyridae). II. Interaction of electric organ discharge activites of two fish. Anim. Behav. 21, 501-512 (1973)

Russell, C.J., Myers, J.P., Bell, C.C.: The echo response in Gnathonemus petersii (Mormyridae). J. comp. Physiol. 92, 181-200 (1974)

Scheich, H.: Neural basis of communication in the high frequency, electric fish, Eigenmannia virescens (Jamming Avoidance Response) I, II, III. J. comp. Physiol. 113, 181-255 (1977)

Scheich, H., Bullock, T.H., Hamstra, R.H. Jr.: Coding properties of two classes of afferent nerve fibers: high frequency electroreceptors in the electric fish, Eigenmannia. J. Neurophysiol. 36, $39-60(1973)$

Taverne, L.: Note sur la systématique des poissons Mormyriformes. Le problème des genres Gnathonemus Gill, Marcusenius Gill, Hippopotamyrus Pappenheim, Cyphomyrus Myers et les nouveaux genres Pollimyrus et Brienomyrus. Rev. Zool. Bot. Afr. 84, 99-110 (1971) 